\title{
Refugee Food Insecurity \& Technology: Surfacing Experiences of Adaptation, Navigation, Negotiation and Sharing
}

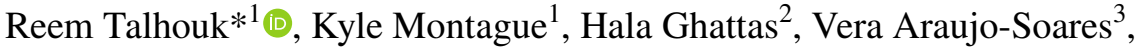 \\ Balsam Ahmad ${ }^{4} \&$ Madeline Balaam ${ }^{5}$ \\ *l Northumbria University, Newcastle upon Tyne, UK (E-mail: reem.talhouk@northumbria.ac.uk); \\ ${ }^{2}$ Center for Research on Population and Health, American University of Beirut, Beirut, Lebanon; \\ ${ }^{3}$ University of Twente, Ensechede, Netherlands; ${ }^{4}$ Population Health Sciences Institute, Newcastle \\ University, Newcastle upon Tyne, UK, ${ }^{5}$ Royal Institute of Technology (KTH), Stockholm, Sweden
}

Accepted: 4 February 2022

\begin{abstract}
With the Syrian crisis still ongoing, 91\% of Syrian refugee families in Lebanon do not have adequate access to safe and sufficient food. There has been a drive for technological innovation in humanitarian food assistance. To further inform such innovation, we used an ExperienceCentred Design approach to gain a holistic understanding of the experiences of refugee food insecurity and how refugees envision technologies can support them. Design engagements with 13 women in an informal refugee settlement in Lebanon were conducted. The findings presented in this paper highlight that coping with food insecurity consists of experiences of adaptation, navigation, negotiation and sharing. We found that a multitude of technologies may be designed to enhance the aforementioned experiences and enable refugees to better cope with food insecurity. Through the lens of our findings, we discuss how technologies may support information sharing, the furthering of new practices and sharing of resources to support refugee food security.
\end{abstract}

Keywords: Digital humanitarianism, Humanitarian innovation, Design, Food security, Humancomputer interaction, Refugees

\section{Introduction}

Lebanon, a neighbouring country to Syria, currently hosts around a million Syrian refugees (UNHCR 2020). A recent Vulnerability Assessment of Syrian Refugees in Lebanon (UNHCR, UNICEF and WFP 2019) found that $63 \%$ of Syrian refugees in Lebanon are marginally food insecure and $28 \%$ are moderately food insecure. Food security is when people have access at all times to sufficient, safe, nutritious food, as defined by the World Food Program (WFP), the primary humanitarian agency providing food aid. 
Improving the livelihoods of Syrian refugees is the most direct way of improving refugee food security. However, the policies adopted by the Lebanese government have restricted the economic opportunities of refugees to the construction and agriculture sectors - both of which entail unstable incomes as refugees are hired on a day-to-day basis (Chamaa and Yassin 2016). Furthermore, the collapse of the Lebanese economy and the political and social tensions in relation to refugees seeking employment has made livelihood interventions difficult to implement within the country. Therefore, the current primary method of supporting refugee food security is through the provision of food aid by humanitarian agencies such as the WFP.

The WFP has been leading in deploying technologies for the delivery of food aid. At the time that this research was conducted the WFP was (1) running an e-voucher system (Talhouk et al. 2020), in Lebanon, to distribute food aid through the use of debit cards that can be used by refugees to purchase food in specific registered shops and (2) piloting a system, in Jordan, that mimics the e-voucher system but with blockchain technologies facilitating refugees dispensing their food aid in shops (World Food Program 2018). However, research on digital humanitarianism (i.e. the digitalisation of humanitarian and aid services) has highlighted the added vulnerabilities that may arise as interactions between refugees and the aid system are mediated through technologies. In Lebanon, Talhouk et al. (2020) found that the e-voucher system results in power asymmetries that introduce new vulnerabilities and limit refugee agency. Furthermore, the study identified the need for recentring refugee experiences and practices within the designs of food aid technologies. The research presented in this paper does exactly that. In this paper we present a study conducted with a Syrian refugee community in rural Lebanon through which we explored:

1. How a Syrian refugee community experiences food insecurity in rural Lebanon?

2. How can technologies be used to support a Syrian refugee community in coping with food insecurity?

To conduct the research, we used an Experience-Centred Design approach (Wright and McCarthy 2010) over the course of a year through design engagements with 13 women residing in an informal refugee settlement in Lebanon. Such a dialogical, empathetic and responsive approach has proven to be invaluable in conducting design research with refugees (Talhouk et al. 2019a).

Our findings highlight how the refugee experience of coping with food insecurity consists of practices of (1) adaptation, (2) navigation, (3) negotiation and (4) sharing from which we draw design considerations for technologies. We contribute to CSCW and HCI literature insights towards how technologies may support refugee food security by meeting their informational needs and facilitating new practices and sharing. 


\section{Related work}

In this section we present a synthesis of relevant literature within the field of HCI \& CSCW in which we situate our findings. We draw on research that highlights the role of technologies in supporting refugees residing in similar contexts to that of our participants as well as explorations of poverty and food insecurity, in nonrefugee contexts, from which technological designs have been derived from.

\subsection{Refugees' technology use in Jordan, Iraq \& Lebanon}

Research has shown the integral role that technologies play in refugees' lives. Coupled with the turn towards digital humanitarianism, we find an increased interest in research exploring how technologies are/may support refugees in their migration journeys (Sabie et al. 2021). Such literature provides a basis from which we can explore potential technological futures in relation to refugee food insecurity. In this section, we focus on research conducted in refugee camps and settlements in the geographic region of the 'Middle East' as that is the context in which our research was conducted.

There has been a plethora of research that has focused on the information and communication behaviors of Syrian refugees in Za'atari camp in Jordan. Maitland and co-authors (Maitland et al. 2015; Xu and Maitland 2016) identified that mobile phones are the most commonly used tool to access the internet, social media, Google and Wikipedia. Yafi et al.'s (2018) study concluded that the technological hacking practices of refugee youth in Za'atari camp was highly gendered, with boys and young men engaging in the activity to help other community members. Boys and young men engaging in these practices were considered to be technology experts within their community and were connected to a larger learning environment.

In Iraq and Jordan, research (Nabil et al. 2018; Sabie et al. 2017) has highlighted how technologies can be used in the making and designing the living spaces of refugees and internally displaced communities to increase refugee agency, autonomy and expressions of identity. In Lebanon, Talhouk et al. (2016), showed the centrality of mobile phone technologies in accessing healthcare services and health information. Furthermore, they (Talhouk et al. 2017), demonstrate how mobile phone technologies can be used to improve access to healthcare information while increasing refugee agency within their relationship with healthcare providers. Lastly, research conducted with Syrian refugees in Lebanon emphasized the need for technologies to facilitate and mediate dignified interactions for refugees (Talhouk et al. 2019b).

\subsection{Technologies for food security}

We also situate our research within HCI \& CSCW research that has investigated the design and use of technologies in contexts of food poverty/insecurity. 
Technologies have been deployed as a means of addressing food insecurity and food poverty in non-migration contexts. Working with a low socio-economic community in the U.K., Prost et al. $(2018,2019)$ introduce the concept of 'food democracy' that accounts for the values of social and economic justice in the production and consumption of food in local food networks. The authors identify the difficulty within such networks to provide food at cheaper costs without negatively impacting local food producers (Prost et al. 2018); thus highlighting the influence of competing needs of stakeholders on food prices. In the U.S., Dillahunt et al. (2019) showed that sharing economy models that enable the online delivery of groceries can support communities in accessing healthy food at a low cost. Indeed, sharing economy models have been identified to have the potential to address limited access to resources as well as social inequalities (Botsman 2014). Such rhetoric further encourages the exploration of sharing economies as an alternative economy that aims to address food insecurity.

Grimes et al. (2008) investigated how a mobile phone technology can be used by low income African-American community members to share and reflect on memories of attempting to make healthy food choices. This research was further extended to exploring how such technologies can support activism around the impact of poverty on ability to secure healthy foods (Parker et al. 2012). Research has also identified that often within food-insecure contexts, technologies can play a role through supporting local organizations providing food aid (Dombrowski et al. 2013). The centrality of local organizations in supporting communities in accessing food as well as being a space for knowledge exchange and building of social relationships has been emphasized (Dombrowski et al. 2013). Within these contexts, digital storytelling and knowledge exchange can support communities in learning how to cope with poverty and accessing aid from the organization (Vyas and Dillahunt 2017).

More specifically on technologies for refugee contexts, few have looked at the role of technologies through the lens of food security. Fisher et al. (2017) has explored the possibility of co-designing a digital cookbook with refugees in Za'atari camp. However, the project aimed to maintain recipes and food heritage rather than address the ability of refugees to access food (Fisher et al. 2017). Other projects have theorized how community mapping activities in Za'atari camp, mediated by technologies, can aid in mapping of food aid (Schmitt et al. 2016; Xu et al. 2015) however community mapping in regards to food security has not been implemented. Irani et al. (2018) identified that refugees in the U.S. face challenges in accessing food due to the lack of availability of critical information about food stamps and due to the language on food packets being in English. In Lebanon, Talhouk et al. (2020) examined interactions of a refugee community with the WFP's e-voucher system. The study showed how the digitalization of food aid results in social and informational power asymmetries between refugees and shop owners, the dispensers of food aid, and as such 
introduce vulnerabilities. Furthermore, the research highlighted the mismatch between the values embedded in the e-voucher system, as a humanitarian technology, and that of the refugee community. This mismatch resulted in interactions that further the vulnerability of refugees and inhibits the collective practices that refugees engage in. The findings from this study highlight the need to reenvision technologies that support refugee food security from the perspective of refugees, their practices and experiences.

Given that food insecurity is intertwined with experiences of poverty, we also situate our research in relation to CSCW and HCI research that investigate how technologies may support communities in coping with poverty. Vyas et al. (2016) identified that households employ various planning and expense tracking systems that incorporate routines, values and familial relationships to better manage their finances. The study posits that familial interactions should be accounted for when designing technologies that aid in meeting both short-term and long-term financial goals (Vyas et al. 2016). More specifically for low socioeconomic status (SES) communities, individuals have been found to employ social networks to barter skills for non-monetary benefits, carpool to visit markets and to share information of product prices (Vyas and Dillahunt 2017). These identified practices further contribute to building the case for sharing economies as a means of facilitating coping with poverty (Vyas and Dillahunt 2017).

The aforementioned studies shed light on how technologies may support lowincome communities in coping with food insecurity and food poverty. However, such research has yet to be conducted in the context of refugees in informal settlements, which is warranted given that research has identified that food aid technologies need to account for refugee experiences and practices.

\section{Methods}

We adopted and Experience-Centred Design approach (ECD) to explore a Syrian refugee community's experiences of food insecurity in rural Lebanon and how technologies can be used to support a Syrian refugee community in coping with food insecurity. Using an ECD approach facilitated reflection and dialogue, among participants and with Reem (first author) on the interactions of participants with their food environment and other elements within their social, political and cultural contexts that impact their food security.

ECD calls for a dialogical, empathetic and responsive approach to design where the values, practices and experiences of participants are reflected upon in a humane manner (Wright and McCarthy 2010) that is conducive to reaching a shared understanding of the issue and aspirations being designed for and with among participants and the researcher. Talhouk et al. (2019a) highlight the need for employing such approaches within refugee contexts as they: (1) create a safe space for both the participants and designer/researcher; (2) facilitate the reaching 
of a shared understanding of the research and (3) facilitate the flexibility of the research and design process in a manner that is responsive to participants' preferences, wants and needs. As this study is part of a larger project that has adopted a community-based approach, only one refugee community was engaged in this research. While engaging with one community and adopting an ECD approach allowed us to gain a deep and holistic understanding of the participants' experiences of food insecurity, similar research with other refugee communities is needed to establish the generalizability of the findings.

Ethical approval was obtained from Newcastle University's Ethics Committee and the American University of Beirut's Institutional Review Board.

\subsection{Recruitment}

We conducted the research in an informal refugee settlement in rural Lebanon. The selection of the settlement, for participation in the research, was done in collaboration with a local Non-governmental Organization (NGO) that was responsible for coordinating humanitarian response in the region and a local municipality leader. The settlement was selected based on the local NGO worker's and local municipality leader's perception of the safety of the settlement. Approval to visit the informal settlement was obtained from the local municipality and Lebanese Ministry of Public Health. Reem then visited the settlement and knocked on every door of the settlement and explained the study to the women within the households. Only women were recruited because: (1) men are usually outside the settlement working/seeking work during the daytime and (2) food preparation and purchasing in Arab refugee households is a gendered role (Chaaban et al. 2015), and therefore women more easily respond to food related questions when compared to men. We obtained oral consent from the 13 women (p1...p13), all of which had children.

\subsection{Data collection}

Data collection was carried out in Arabic, the mother tongue of all participants and Reem. All data collected through the study activities were audio-recorded. We conducted the research over the span of multiple engagements that are detailed below.

\subsubsection{Introductory engagement}

Reem conducted the introductory engagement with each participant individually to build rapport with participants and to ensure that each participant's voice is considered when co-constructing a shared understanding of: (1) the study objectives, (2) how participants want to go about conducting the study (i.e. the 
different data collection tools we can use) and (3) what is the community benefit from engaging in this research.

Accordingly, Reem provided participants an overview of the possible methods that can be used and topics to be discussed as part of the project. Methods included traditional focus groups and interviews, dialogue cards, diaries and the co-designing of an artefact that would reflect their work in the design process.

Each participant provided feedback regarding which methods they preferred. This resulted in: (1) the use of dialogue cards (Figure 1) for narrative building as a primary method; (2) the cocreating of a booklet; and (3) the use of diaries by some participants.

Dialogue cards The dialogue cards were designed to facilitate dialogue within the engagements around participants' experiences of food insecurity as well as facilitate in the co-construction of narratives of coping with food insecurity at a community level and in relation to technology. The cards were created based on the Arab Family Food Security Scale (Ghattas et al. 2018) and were intended to reflect the multiple factors that might influence food insecurity and coping with food insecurity. The cards were color-coded by category including (see Figure 1): (1) Food coping strategies in purple; (2) People within the refugee community and the host community in yellow; (3) aid organisations they interact with in navy blue; (4) Types of food \& dishes that range in cost, in red; (5) Seasons that are known to have an impact on

Figure 1 Examples of dialogue cards used. (1) purple card: decreasing portion size as a coping strategy, (2) red card: meat dishes, (3) light blue card: smartphone, (4) green card: winter, (5) navy blue: NGO workers, (6) yellow: shop owner, and (7) brown card: gas cannister

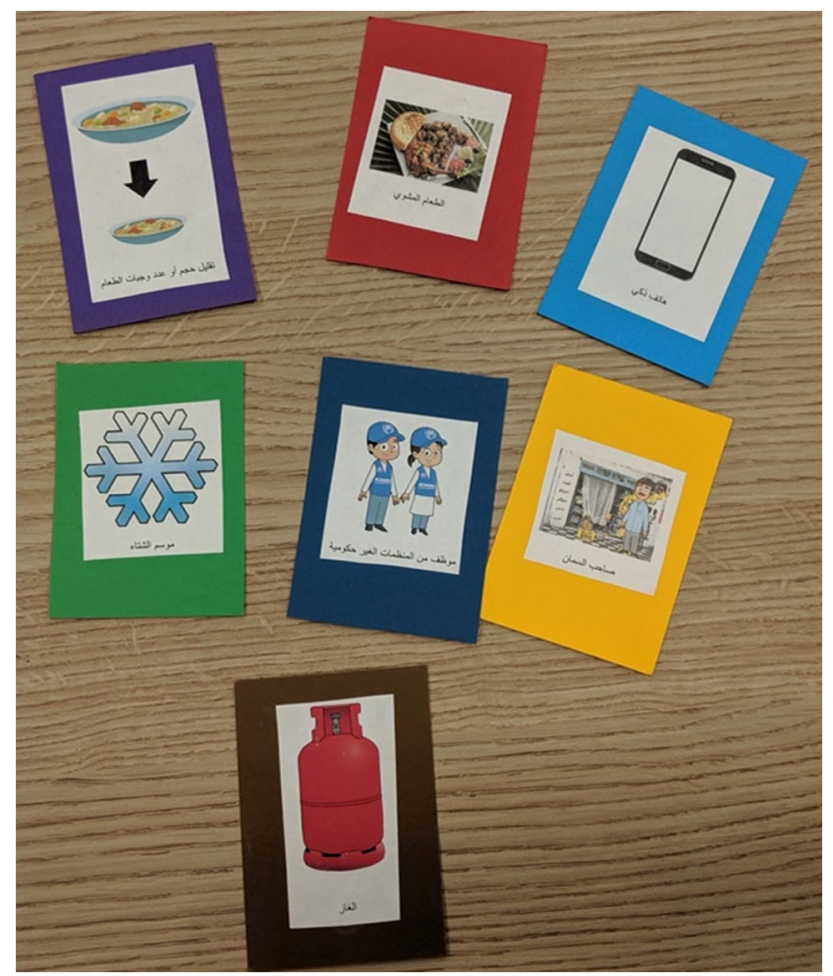


refugee food security, in green; (6) Resources needed for the preparation and preservation of food, in brown. Additionally, Reem created cards that represented technologies that are commonly available to refugees (UNHCR 2016) in blue. Participants could also create new cards which resulted in 10 new cards being made. The dialogue cards also provided an opportunity for Reem to partake in the discussions and use the cards to co-construct narratives reflecting her grandparents' and parents' experiences of food insecurity during the Lebanese civil war and her food experiences while living abroad.

Cocreating a booklet It was agreed on with participants that one of the outcomes of this study will be a cocreated booklet that would reflect the data that participants have shared and that can be used by the community to discuss food insecurity with NGO representatives that assess their food security. The co-creation of the booklet acted as a reciprocated probe (Wallace et al. 2013) that reflected Reem's responsiveness to participants and the experiences they are narrating. Also, the booklet was considered by participants to be a tool that they can use for advocacy.

Diaries Three participants indicated that they would like to fill in diaries of their experiences of food insecurity with one participant stating that she would enjoy drawing depictions of their experiences. Consequently, Reem made diaries that were given to participants. The diaries consisted of both blank and lined pages as well as a blank cover.

At the end of the introductory engagements, some participants indicated that they were still unclear on the different aspects of their experiences that the research would surface. Therefore, Reem suggested to participants that she can run a follow-on introductory design engagement individually, in which participants can begin discussing some aspects of experiences of food insecurity. This was to give participants a better sense of the conversations that may take place during the study.

Lastly, participants and Reem agreed that her fluency in both Arabic and English enabled her to provide a meaningful outcome to the community by tutoring the children. Agreeing to do so can be seen to be in line with responsiveness as an element of ECD. In order to avoid such a form of beneficence becoming coercive, Reem offered to tutor all the children in the settlement regardless of the participation of their mothers in the study. This resulted with Reem tutoring 20 children, five of which their mothers did not participate in the study.

\subsubsection{Introductory follow-on engagement}

As previously mentioned, the aim of this engagement was to give participants more of an idea regarding the topics we will be discussing and how we will be using the dialogue cards. To do so Reem introduced the food coping strategies cards and participants were asked to sort the cards based on the strategies they are engaging in and reflect on their choices. Participants were asked to arrange them based on the coping strategies that they preferred employing (with the most preferable being the first) (Figure 2) and then based on the effectiveness on the coping strategies. Additionally, participants were asked to group coping 
Figure 2 Showing cards representing coping strategies sorted based on preference with working more being the most preferred strategy (furthest on the left) followed by decreasing food quantity and relying on cheaper foods, decreasing expenditure on health and education, borrowing food/relying on help from friends and family, borrowing money and the least preferrable being not being able to do anything

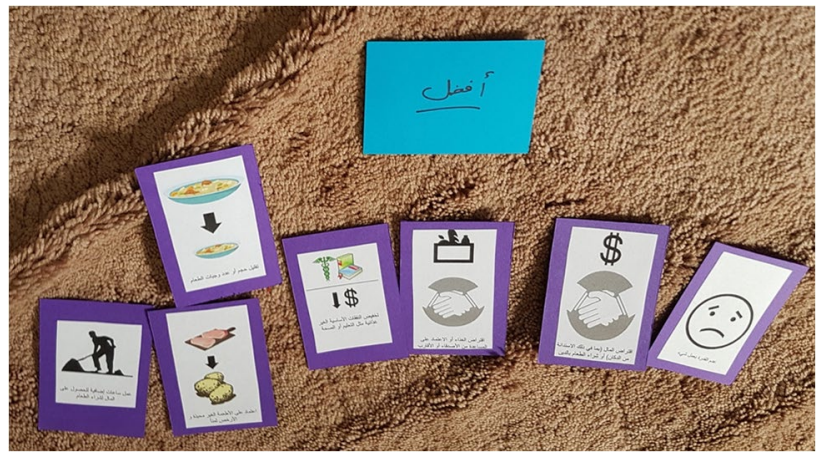

strategies that they employed simultaneously together. At the end of these sessions all 13 women agreed to continue participating in the study.

\subsubsection{Configuring a space for the design engagement}

After refining the tools and design process to match the preferences of participants, Reem met with participants to give them a detailed overview of the data collection process. Reem also discussed with participants the frequency of her visits for both the design engagements and to tutor the children. Reem showed participants the different materials that will be part of the data collection (e.g. big cardboards to take notes of their discussions, place the dialogue cards when co-constructing narratives and to present back findings from other participants). Throughout this process participants were asked to suggest any changes to the data collection process as they saw appropriate.

\subsubsection{Narrative building engagement}

The aim of this engagement was to facilitate dialogue and the co-construction of narratives among participants regarding their experiences of coping with food insecurity, at a community level, and how technologies may support their food security. The cards were divided amongst participants and they placed the cards in relation to one another in order to construct individual and collective narratives that reflect their experiences of food insecurity (Figure 3). The technology

Figure 3 Dialogue cards placed by participants in the engagement to co-construct narratives of food insecurity and coping

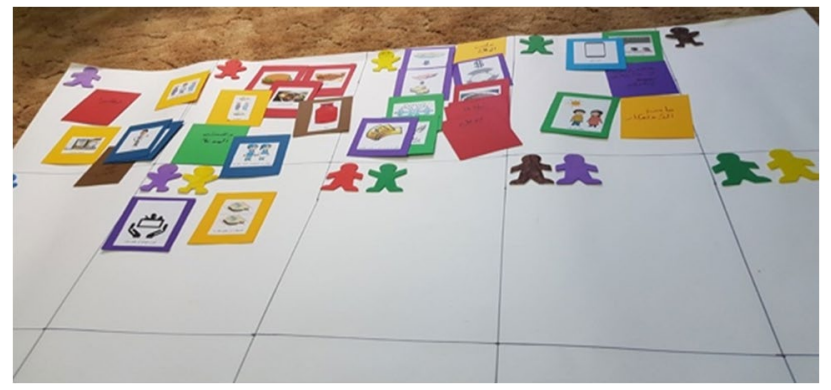


cards were used by participants to reflect on how technologies are supporting them in coping with food insecurity as well as to ideate how they may further support them. Throughout the engagements Reem would reflect on their narratives and share how they relate to her experiences as well as the experiences of her parents and grandparents during the Lebanese war.

\subsubsection{Validation/Member checking engagement}

After the co-construction of narratives, Reem conducted a validation engagement (Creswell and Miller 2010) to ensure that the primary themes from her initial data analysis were true to participants' experience. To do this she collated anonymous quotes reflecting major themes and presented them back to participants (Figure 4). Participants critiqued, added and removed data. The engagement also aimed to show reciprocity by reflecting to participants that their experiences are being accurately heard and understood.

\subsubsection{Content-design engagements}

Reem then conducted two content design engagements. The aim of the first content design engagement was twofold. The first was to work with participants to put together the data collected into sections that would make up the co-created booklet. Secondly, the engagement was designed to instigate further reflection and dialogue among participants regarding the narratives they co-constructed and to give an opportunity for participants to add any experiences that they felt were not previously fully explored. Participants used a white cardboard to prescribe how the data should be divided in to different parts of the artefact. Three participants also volunteered to draw images to be used in the booklet. In the second engagement, Reem presented to participants a draft of the booklet and the content of the artefact was further validated by participants.

Figure 4 Collated quotes that represented themes that were adapted and amended by participants in the validation engagement

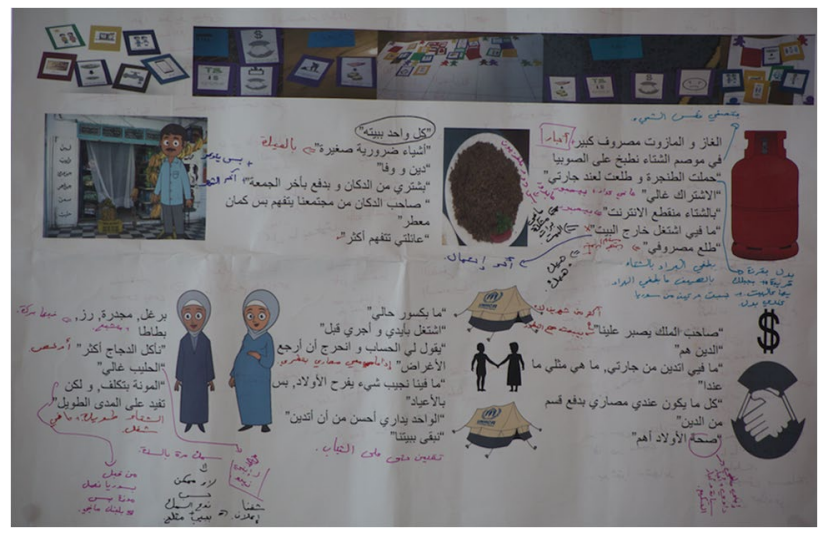




\subsubsection{Wrap-up engagement}

The aims of this engagement were to (1) collect participants' feedback regarding the methods and research approach employed in this study, (2) discuss with participants the next step of the project and (3) present to them copies of the final printed version of the booklet. To elicit feedback regarding the methods, Reem did a recap of all the methods used and she explained to participants that one of her aims as a researcher is to learn how to do this type of research better. She then asked participants to voice their opinions regarding the methods as well as how we could have done things differently. During this engagement, she also discussed with participants what the possible next steps were for the project and how the discussions around technologies may contribute to addressing their food insecurity. Participants and Reem agreed that more time is needed to consider how to move forward with possible technological designs.

This study was followed by another study in which we investigated how we may reconfigure existing food aid technologies to embed the communities' values and practices as a means of countering the vulnerabilities introduced by the digitalization of food aid.

\subsection{The booklet}

The engagements led to the co-creation of a booklet entitled, "The Suffering of Syrian Refugees: 'Despite the Austerity, We are Living'”. Participants discussed wanting the title to reflect that coping with food insecurity is an ongoing struggle intimately attached to their status as refugees and poverty, while also indicating that they are surviving through it. The online version of the booklet in Arabic and English can be found at the following link: https://refugeefoodsecurity.wordpress. $\mathrm{com} /$.

The data were divided into chapters in a chronological manner that reflected participants' displacement journeys, as well as seasonal changes that affect their food security. The first two chapters were dedicated to the interplay between their experiences of displacement and food security. It is in these two chapters that participants highlighted the need to obtain local knowledge regarding purchasing of food and the town they have resettled in. The next three chapters were seasonal chapters and focused on experiences and practices utilized during school time, the holy month of Ramadan and winter. These seasons were selected as they each introduced new factors that they needed to account for when purchasing and preparing food (e.g. less income in the winter season). In these chapters, the advice provided to other women focused on how to prepare for these seasons and to cope with food insecurity. They emphasized how to navigate and negotiate aid and transactions. Participants wanted to end the booklet with a positive note and therefore opted to have the last chapter titled "We wish". In this 
chapter participants stated that they wish they can go back home to Syria and that the Lebanese host community would understand their situation and refugee experiences.

\subsection{Data analysis}

We transcribed and translated the audio recordings from the design engagements to English. The corpus of data was supplemented by data from the diaries. Thematic analysis (Braun and Clarke 2013) was conducted using Nvivo (11.4.2). The data analysis was conducted by the Reem. First the corpus of data was reviewed and coded. Codes were then validated with another co-author and grouped in to themes.

\section{Findings}

Our findings indicate that for this refugee community coping with food insecurity consisted of experiences in which they adopted new practices to support them in adapting to their new locations and households, navigating the aid system, negotiating with food shops and service providers and sharing resources. Furthermore, although participants initially indicated that technology was not playing a key role in helping them cope with food insecurity, through the engagements we identified how technologies can support them in furthering practices that help them meet their food needs. It is important to note that while the co-constructed narratives were centred on food security, participants highlighted that their experiences of poverty (that are not directly food related) influenced their experiences of food insecurity.

\subsection{Adapting}

Participants co-constructed narratives that highlighted that they experienced an adaptation curve in which they had to adapt to their new context of displacement and poverty and then the new households that they formed once displaced.

Participants identified that they initially had to adapt to not having the means to be food secure:

'Back home I had my house. We had our business. We did not have to worry about money and food' (P5).

'In Syria, we were well off but I moved here, we have to adapt to live with what we have' (P12).

Participants viewed that understanding how they have adapted as essential in understanding their experiences of food insecurity as that adaptation resulted in the adoption of new practices based on their new geographical location and to the new households they formed in Lebanon. 


\subsubsection{Adapting food shopping practices to new geographical locations}

Participants used cards representing members of the Lebanese host community to emphasize that being displaced to new geographical locations led to an adaptation of their food shopping practices.

Knowledge of towns that were perceived to be more welcoming to them was communicated through word of mouth by relatives and other refugees who had previously visited and/or worked in the town before the war in Syria began. Participants recounted narratives of moving from town to town until they found a town in which they felt safe:

'I first lived in Daya'a but we heard that this town treats refugees better so we moved here' (P1).

Participants highlighted that feeling safe in their new location influenced whether they or their husbands practised food shopping. They narrated that in Syria they would normally do the food shopping, however, when they moved to new towns their husbands started practising food shopping because they felt vulnerable and unsafe as refugee women to go out in their new towns. This highlights the gendered adaptation of food shopping practices in their displacement to Lebanon. However, the women indicated that this change in practice made it difficult to cope with food insecurity. Given that the men did not have the role of cooking in the household, they would not know what ingredients to swap for cheaper ones:

'At first he [her husband] would go the shop and of course he doesn't know what items to swap ingredients with if something was expensive' (P12).

As the women adapted to their new town, they became more comfortable in reverting back to practising food shopping themselves.

\subsubsection{Adapting practices of discussing food expenditures to new household structures}

As participants were displaced, they also had to adapt to new household structures that formed with their extended families:

'I was living alone and then, all of a sudden, I found myself living with several other families' (P2).

Adapting to living in new household structures entailed changes in food habits that warranted new practices related to more openly discussing 
household finances. Participants reflected on how living with extended family members impacted food habits and ultimately their food expenditure:

'My son would have already eaten, but then he would see his cousins eating and he would want to eat again' (P1).

'when we were living alone one loaf of bread was enough for a week, but when my sister-in-law lived with us we would buy three loaves a day' (P9).

Participants indicated that they had to adapt to such new food habits by adopting practices related to openly discussing food expenditure within their household, which was not commonly done with their extended family members when they lived in Syria. This was especially true as they realized that they had to start keeping track of who bought what and learn 'how to control our expenditure' (P12). Consequently, they adapted to this by having open discussions about finances within their new households. The practice of more openly discussing finances was further expanded to seeking advice from other women outside their new households regarding how to manage food expenditure:

'[You need to] Discuss household expenses with other household members and seek advice from other refugee women' (P12).

'The lady [her neighbour] used to tell me get this or don't get that and for example, when a guest comes get and do whatever you can afford, you don't have to borrow money' (P10).

During the data collection process, we observed participants continuously advising each other on how to make the most of their money when food shopping. Participants highlighted that they benefited greatly from the knowledge of others as they were adopting new practices of talking more openly about their household finances.

\subsubsection{Technologies for adaptation}

Participants discussed how technologies could play a larger role in supporting them in adapting to their new contexts of food insecurity by facilitating the sharing of experience-based knowledge of refugees that had arrived before them. Participants acted on this idea by requesting that the co-created booklet be digitized and made available online after it was completed so that they could share their experiences and advice with others:

'It would be better if we put the booklet on the internet and Facebook or else no one will read it' (P13).

'That way we can show it [the booklet] to others' (P12).

'Yes, I can share it [the booklet] on Facebook and WhatsApp' (P8).

Therefore, Reem made a website to host the booklet and that was shared with refugee participants for them to disseminate within their social networks.

Other than supporting the sharing of knowledge, participants identified that technologies may support them in adapting to their new need of becoming two 
income households. Indeed, participants indicated that given their new context of displacement and poverty they were beginning to explore how they can contribute to the household income, 'to help buy the things we need' (P3). Two participants said that they had attempted to use Facebook to find jobs so that they could contribute to their household income and therefore cope better with food insecurity. However, both indicated that it had not been helpful:

'I saw on Facebook there was a job that I can do, I have a degree in administration you know [she had not previously held a job in Syria], but when you click on it you see that they want you to go to Beirut [a 4 hour drive from the settlement] for the interview... I couldn't do that (P2).'

'We have children so we can't leave our homes to go to work, but I keep looking on Facebook to see if there are jobs I can do while I am at home. But I haven't found anything' (P5).'

A participant, P5, who had previously worked as a hairdresser before getting married elicited the Reem's help to set up a Facebook page. She wanted the page to market the hair salon she was intending to run from her house. However, she did not know how to use Facebook in that capacity.

\subsection{Navigating aid systems}

While the research mainly intended to focus on experiences of food insecurity, participants co-constructed narratives of difficulties in navigating the wider aid system and not just the food aid system. This was due to them not differentiating between the food aid system from the rest of the humanitarian system. They would refer to all aid as aid from the United Nations. Furthermore, participants recounted narratives of navigating donation systems in which they developed specific practices to help ensure that they have access to the donations.

\subsubsection{Difficulties in navigating the aid system}

Participants were eager to provide feedback regarding the aid system and highlighted the difficulties in navigating the aid system in a manner that allows them to practice long-term planning of their resources and food purchases. They identified that the first hindrance to navigating the aid system was gaps in their understanding of it. Several participants indicated that they have recently received aid but were unaware of the amount or type of aid they were receiving through the debit cards that are topped up by aid organizations:

'They [an aid organization] gave me a red card [a debit card] but it has not been activated yet and we don't know what it is for [if it is for food purchases only or cash assistance]' (P3).

'This month they have registered us again for aid but we don't know what they want to give us. We don't know' (P13). 
Furthermore, participants were questioning how aid is distributed and the kind of aid distributed:

'People get fuel, I don't get any and I don't know why. They don't tell me why I am not entitled to aid' (P11).

'Why do I get cash and other people have vouchers?'(P7).

Participants identified that such gaps in understanding of the aid they are receiving makes it difficult for them to rely on aid as part of their long-term financial planning for food security.

\subsubsection{Practices for navigating donation systems}

Other than aid provided by the aid system, participants also co-constructed narratives around donation systems that they often access for aid to improve their food security. Narratives showed that sometimes people in the town and other neighbouring towns give away donations in the form of clothes or food. The type of aid varied depending on the donations being made; one month they would donate clothes the other month they would donate food. Participants emphasized that when engaging with such donations they adopt the practice of always going to get aid even if the aid is not food related. They adopted this practice so that the donors remain familiar with them and maintain their names on their rosters. This familiarity was considered necessary for them to ensure that they can benefit from food donations once they are made:

'Even if it is summer clothes being given out in the winter we go and take them because next time it might be food' (P12).

The practice of accessing non-food related donations was considered essential in ensuring that participants can access food aid when it is available. One participant recounted how failure to do so makes it harder to access food when it is donated:

'My husband went and he stood in line the first day; and the second day; and they didn't give him aid. He said "why didn't I get aid?" They told him "no [you are not eligible because] you have not come here and taken aid from us before [during a previous charity donation]". He told him, "no one is telling me when there is food aid." How is he supposed to know?" (P10).

Additionally, participants indicated that due to the 'corrupt' gatekeepers of the donations being made they often have to accept the practice of paying the gatekeeper to receive the donations. They recounted that donations are usually pooled by one person who the donors have entrusted with their distribution. Multiple participants narrated how they had been extorted by such a gatekeeper to pay a commission on the donations he was distributing. 
'we have to pay the person in charge 5000LB (\$3.3 U.S.D) so he will give us aid' (P13).

They discussed how they knew that he was pocketing the money however could not challenge him from fear of being unable to access aid in the future:

'We don't dare complain because then he will mark our [the people in our] building [as trouble makers] and we won't get any more aid. It has happened with others [gatekeepers]' (P7).

Such narratives indicate that navigating the aid system entailed participating in specific practices to ensure future access to food aid.

\subsubsection{Technologies for navigating aid}

Participants co-constructed narratives where they highlighted a gap in their understanding of the aid that they receive. Accordingly, they identified that there is space for technologies to contribute to more transparency and responsive feedback mechanisms within the aid system. Several, participants indicated that they only received an SMS informing them that their aid has been discontinued. When they then visited aid organizations and asked why their aid was discontinued, the aid workers would respond by saying 'Someone pressed the wrong button by mistake' (P5) without any further explanation. Furthermore, participants identified that the current remote feedback and query process, in relation to aid and donations in place is ineffective, 'We call but no one picks up' (P4). Consequently, participants discussed how technologies may support them in having more responsive dialogue with the aid system and donors through which they can effectively query their aid status and report gatekeepers restricting their access to aid.

\subsection{Practices of negotiating transactions}

Co-constructed narratives reflected practices of negotiating transactions that ensure that participants have resources available to purchase food. Participants recounted how negotiating payments to be made to service providers as an essential practice. Furthermore, participants reflected on how they negotiate the use of their food aid in transactions with shop owners. Such narratives also highlighted how their dependency on some shop owners limited their ability to negotiate for lower food prices.

\subsubsection{The practice of negotiating with service providers}

Reflecting on interactions with members of the Lebanese host community, participants built rich narratives of their dependency on practices of negotiating payments to service providers within their host communities. While such practices 
are not directly related to accessing and/or purchasing food, they ensure that they have some resources available to them to purchase food when needed (e.g. when income is low in the winter).

Cards representing service providers were created with participants showing their centrality in their food insecurity narratives. Participants' narratives reflected the practice of negotiating making payments in instalments with service providers that are understanding of their situations. Participants elaborated that the landlord is patient regarding tenants paying their rent late especially in the winter when job availability in the construction and agriculture industry is limited, 'The owner of the building is good to all' (P6). They indicated the same regarding the owner of the generator that provides them with electricity during the hours in which there is electricity rationing and the school bus driver:

'I have money I give him. When I don't have money... sometimes I am 3 months late [in paying him] but he is patient' (P1).

They attributed this understanding from service providers as a form of aid that stems from these individuals being 'considerate of our [their] situation' (P1) and from the same neighbourhood, 'We are all in the same neighbourhood. He knows us and we know him' (P5). However, participants indicated that this practice leaves them vulnerable to instalments being recalled at times unsuitable for them. One participant indicated that the bus driver often sends them an SMS asking them to pay at unexpected times:

'he tells the children, "Tell your parents you owe this much etc.", and if the children didn't tell us he would send us a message on the phone' (P1).

Furthermore, participants are not able to practice such a negotiation of payments with all service providers. When integrating the season cards within their narratives, participants indicated that when income is limited, they discontinue their Wi-Fi in order to cut down on expenditures as they are unable to negotiate with the Wi-Fi provider.

\subsubsection{The practice of negotiating with local shop owners}

More central to their food security was the practice of negotiating with local shop owners and the use of their food aid that they often felt unable to do due to their dependency on some shop owners.

Participants indicated that there is a whole economy based on the practice of selling food vouchers, given to them by aid organizations, for cash. However, all but one participant recounted that they do not engage in the selling of their vouchers. They highlighted that they do not sell their food vouchers so that the landlord does not perceive the food vouchers as a means for them 
to attain cash and pay rent at the expense of food. They did however, indicate that some shops in which they use their food vouchers allowed the practice of purchasing non-food items using the vouchers; all the while inputting in to the voucher system that the purchased goods are food items:

'We also use the food vouchers to buy cleaning detergent for the house, don't we need those?' (P8).

In this instance, we find a negotiation taking place between participants and shop owners in order to establish a loophole in the aid system that provides refugees with more agency regarding the use of their food aid. However, participants indicated that not all shop owners engage in such practices of negotiating the use of their food aid. This places them at a disadvantage as shop owners that they are reliant on for such negotiations have knowingly increased their prices. Participants viewed this dependency as a challenge in negotiating for lower prices:

'He is more expensive but I can use the voucher to buy washing liquid' (P1).

'I can't tell him sell it to me for 2,000 L.L. instead of 3,000 L.L. because I am not paying with cash' (P5).

Furthermore, participants indicated that there are several other factors that restrict their ability to practice the negotiation of food prices. Some households identified that very few in the community have cars and therefore their access to competitive prices is limited to the shops in their direct vicinity. When asked by Reem if they go to the vegetable market for cheaper food, one participant responded by saying 'No, by God, we don't have a car' (P3). Furthermore, even those with cars indicated that travelling to other towns may make them legally more vulnerable as 'We brought our own car with us from Syria, but now it is illegal we can be stopped at a checkpoint' (P4). Participants also highlighted that they find the cost of public transportation prohibitive to accessing shops that are further away. Therefore, their inability to access other shops outside their vicinity makes them more dependent on a few shop owners thus reducing their ability to negotiate for better food prices.

Participants' access to other shops is further restricted by their practice of avoiding shops in which they are treated disrespectfully. Participants highlighted that they have to sometimes choose between shops offering food at better prices and shops in which they are treated with respect. A participant recounted how they could drive to a shop out of town which is much cheaper, however, they dislike going there because the shop owner is disrespectful towards Syrian refugees. Participants narrated how they felt unwanted in some shops and how that influenced their food shopping experience. Refugee participants stated that even if a shop is cheaper, they would not do their shopping there if the shop owner is rude or makes them feel uncomfortable: 
'I don't like him [a shop owner], he is unwelcoming, so I do not shop there' (p13).

'Even if it is cheaper, why should we benefit someone who is rude to us...we should benefit the people that are good to us' (P8).

Negative treatment in shops that may be cheaper dissuaded them from shopping there thus making them more dependent on specific shops where they feel more comfortable, despite higher prices. Participants' limited choice in shops and shopping experiences that are accessible and appropriate furthers their dependency on a select number of shops thus limiting their ability to negotiate lower food prices.

\subsubsection{Technologies for negotiation}

Technology was discussed as a tool to support participants in the negotiations they conduct when purchasing food. Proposed technologies included ones that give them access to the prices of food items beforehand to better equip them in negotiating with shop owners. Participants discussed having a platform through which they could better access knowledge on current food sales and discounts as well as the prices of products in different shops, so that they could make a shopping plan and budget better before going into a shop:

'What a nice idea [having an online list of items and prices]' (P3).

'The list is nice because then you decide I want this thing or I don't want this thing.

Either I can get it or I can't get it. I can decide based on its price' (P5).

Furthermore, participants indicated that they would also benefit from finding online information regarding shop owners, their openness to negotiating prices and how they treat Syrian refugees. Such knowledge shared would help them in negotiating which shop to go to based on prices and expected experiences.

\subsection{The practices of sharing resources}

When discussing experiences of food insecurity in relation to cards representing individuals in their community, participants co-constructed narratives about how they share resources within their households and community. These narratives not only surfaced collective practices but also the factors that inhibit the wider sharing of resources.

\subsubsection{Sharing resources within new households}

Narratives based on cards representing resources and extended family members, highlighted that living with extended family members within their new households enables them to share resources to meet their food needs. One participant explained how they use food vouchers received by her widowed daughter, that is now living with her, to buy food for the whole household. They then rely on her husband's and sons' income to pay for other expenses throughout the month. 
Another participant recounted how when she was living with their extended family:

'One person will manage the money and pay for everything, and at the end of the month the expenses from rent to electricity and food were divided by five because we were five families [living in the household]' (P12). The practice of sharing resources extended beyond households to other members within the community.

\subsubsection{Sharing within the community}

Another key element that was present within the co-constructed narratives was the practice of sharing within the community. Participants provided narratives of sharing material resources used for food preparation and cooking. In one instance, one participant recounted how, when she ran out of gas in the stove, she carried the pots and continued cooking the food in her neighbour's kitchen. Participants also described practices of sharing food. In times of need participants indicated that they borrow small quantities of food from one another, 'Sometimes you have to borrow from your neighbour garlic, onions or rice' (P11). Participants highlighted that borrowing small amounts of food was preferable to borrowing money to buy food, 'If I take it from her it is better than borrowing money' (P13).

However, participants recounted that they can only borrow food from one another in small quantities because 'we are living in the same situation' (P13). Consequently, participants resort to sharing food only in times of need, 'yes, sometimes [when] I need something I send someone to my neighbours or friends to get [it]' (P8). Participants described sharing food resources as a favour system that is practiced in good faith:

'They don't ask for it [food] back but you return it out of good faith because you can't ask for something else if you need it later on' (P6).

'For example, if you are in a tight spot, you need salt you take some from your neighbour and then when she is in a tight spot she takes from you. It is like borrowing and paying back. But you can't just ask for it and she gives it to you without anything in return later. You know what I mean?... it is borrowing food and returning it' (P13).

Other than engaging in the aforementioned system of food sharing, participants discussed how they share money to practice collective purchasing of food. Participants reported that they would often pool cash in order to buy food products that they would not have otherwise been able to purchase:

'Once I wanted to buy a box of tomatoes, but it was expensive, so my neighbour and I bought it together and we split it' (P13).

'We do that, for example if we want to buy olive oil which is expensive, we buy it and divide it amongst us...that way we can afford to pay for it' (P5). 
Two participants also co-constructed a narrative in which they recounted that they sometimes share transportation costs in order to go shopping, 'If I know that she [her neighbour] is going to the market, I go with her' (P2).

\subsubsection{Technologies for sharing resources}

Reem and participants discussed the potential for technologies to support them in the sharing of resources. In this discussion, participants identified that technologies should not encourage the sharing of meals and privately owned resources that are accessed frequently such as fridges. Such restrictions are derived from the notion of maintaining their privacy and a lifestyle in which their children do not feel that they are refugees or different to other children:

'I don't send my children to eat at my relatives, I hope to die before we get to that point.' (P6).

'We don't send our children to other people's homes...Thank god we stay in our house' (P4).

Furthermore, when discussing sharing space and resources, participants identified that they value their household privacy, therefore making it difficult for two households to share a fridge. One participant emphasized that despite her neighbours being akin to her sisters:

'Each household has its own privacy... We are used to living as independent households [back in Syria]' (P13).

Additionally, participants indicated that a barrier to further leveraging the sharing of resources is the consideration that their neighbours are experiencing the same difficulties as they are and therefore do not have resources to spare, 'We are all living in the same conditions' (P12). It is through these narratives that participants explained that with the scarcity of resources available to them, expanding food sharing practices would be difficult. They did, however, identify that technologies may be used to support them in decreasing the costs incurred when purchasing food through sharing transportation and food costs. Only three of the participants had access to transportation. Those that did not saw value in a technology that would facilitate ordering products online and having them delivered to the settlement:

'Delivery would be good for people like me, who don't have cars' (P3).

When prompted to further discuss the possible benefits of online shopping, participants identified that they could order from the same shop and then split delivery costs, which is in line with the current collective purchasing practices that they engage in. Furthermore, participants speculated that technologies can facilitate collective purchasing by enabling them to find items that would be 
discounted if bought in a large quantity. This would result in lower costs for each of them when divided amongst them. Participants commented that items such as laundry detergent may end up being cheaper per kilogram if bought in the larger discounted bags, thus freeing up resources to purchase more food. Through such examples participants highlighted that having information regarding discounts on bulk purchasing would allow them to further leverage their collective purchasing practices and save money.

\section{Discussion}

Our findings show that when considering how technologies may support refugees in becoming more food secure, we need to account to for experiences of adaptation, navigation, negotiation and sharing. Within experiences of adaptation, navigation, negotiation and sharing, participants identified varying informational needs that can be met through technologies to support them in coping with food insecurity. Additionally, the research highlighted new practices that emerge from the aforementioned experiences to cope with food insecurity. Therefore, in the following section we discuss how technology may support the information needs of refugees in relation to food security, the new practices that they are employing for navigation and negotiation and finally the practices of sharing.

\subsection{Designing for information needs}

During their journeys of displacement participants had to adapt to new contexts. Such adaptation required accessing and gaining new information that changed as they progressed through their journeys. Indeed, participants indicated that at different times they had different informational needs. Initially, peer knowledge was exchanged to find safe towns to live in that resulted in them all living in the settlement where this study was conducted. Once settled in the town they currently live in, they exchanged information to identify cheap places to buy food.

Participants highlighted that technologies may enable them to access and share experience-based information that would support their food security as well as the food security of future refugees being displaced to Lebanon. Within $\mathrm{HCI}$ and $\mathrm{CSCW}$, several projects have investigated the design and development of information-sharing platforms in which local information is shared with refugees in response to information gaps in relation to services available to them (Duarte et al. 2018; Schreieck et al. 2017). Here we find a potential for technologies to facilitate the peer-to-peer exchange of refugee experiences and knowledge in a manner similar to that of the co-created booklet and previous literature that identified story telling as a means to support communities in coping with poverty (Vyas and Dillahunt 2017). Furthermore, Duarte et al. (2018) unpack the importance of providing timely information as service 
provision for refugees often changes. Our findings extend on this by highlighting that timeliness is not only important in ensuring the refugees are receiving the right information regarding available services but also in addressing their varying informational needs that differ at different times in their adaptation journeys. Indeed, participants chose to divide the co-created booklet in to chapters for different seasons further highlighting the temporality of their experiences and in turn their information needs. Such a versatile informationsharing platform should go beyond sharing information on services to include information on actual lived experiences of coping with food insecurity, such as experiences of refugee women navigating the new towns they are living in. The sharing of experiences, rather than just information, calls for the co-creation of knowledge in a manner like that employed for the co-creation of the booklet and the advice provided within it. The knowledge shared to cope with food insecurity, as indicated by our participants, should range from general knowledge regarding how to deal with household finances to very local knowledge regarding where to find food at lower prices.

Additionally, when designing information technologies for navigating the aid system, our findings highlight the need for information platforms that enable refugees to provide feedback regarding services and the ability to query aid being provided or discontinued. Recent research has predominantly focused on how technologies can support refugees in navigating their new environments through providing them with geospatial information regarding services and their new city (Almohamed et al. 2018; Baranoff et al. 2015; Duarte et al. 2018) as well as attaining new language skills that will facilitate their resettlement process (Weibert et al. 2019). However, our participants highlighted that the current mechanisms through which they contact aid organizations to query aid, calling and visiting them, resulted in vague answers. Furthermore, participants such as P3 indicated that they have received aid in the form of a red debit card but are unsure what it is for. Participants attributed that such gaps in understanding of the aid they are receiving make it difficult for them to make long term financial plans. Such findings indicate that previous research with low socio-economic communities that recommends the design of financial tools that facilitate users in creating short- and longterm financial goals (Vyas et al. 2016) may not be applicable in this context. Rather, our findings show that for technologies to support refugees in coping with food insecurity they should facilitate transparent responses to refugee queries regarding aid received/discontinued. Such notions are in line with (Dombrowski et al. 2013), where the centrality of relationships between food insecure communities and charities is emphasized.

Lastly, to further support negotiations around food transactions, participants identified that online information regarding the prices of food would support them in better planning their food shops as well as negotiating with 
shop owners. Such information would allow refugees to better select shops with which they can negotiate, especially when coupled with the experiential knowledge regarding how different shop owners interact with Syrian refugees.

\subsection{Designing for new practices}

The co-constructed narratives showed the formation of new practices by participants to cope with their food insecurity. New practices related to discussing finances, changing gender norms, seeking employment and negotiating payments warrant further consideration when designing technologies for food security.

Participants narrated that adapting to living with extended families introduced new ways through which finances were discussed and managed within the household. Previous literature (Kaye et al. 2014; Vyas et al. 2016), has highlighted that financial practices utilized are often related to upbringing and that households develop financial practices to cope with poverty. However, our findings show that within the context of living with extended families refugee participants had to adapt and work together in their new households to form new financial practices that differed from their previous practices. Consequently existing research (Vyas et al. 2016) on designing technologies to support the management of finances within low-socioeconomic households needs to be expanded to account for periods in which refugees suddenly find themselves in new forms of households.

Additionally, our findings highlight certain instances when participants have had to adapt gender norms in relation to food shopping practices to cope with their new context. Such shifts in gender roles is common in refugee settings (ElMasri et al. 2013). Therefore, we need to explore how technologies can support future refugees in such instances of adaptation. Recipe planning, for example, has previously been identified as a practice adopted in order to reduce food waste (Comber et al. 2013). Our findings indicate that flexible planning of recipes in which ingredients are interchangeable is essential in order to cope with food insecurity and is commonly practiced by the refugee women in the community. Projects such as Fisher et al. (2017), in which researchers explored the development of a refugee cookbook as a means of maintaining heritage, may be further enhanced to support the sharing of recipe adaptations in relation to the costs of ingredients. The sharing of such knowledge across gender divides may facilitate the shifts in gender roles when it comes to the practice of food shopping, specifically in contexts where it is perceived unsafe for refugee women. Additionally, the documentation of such recipe adaptations could be further used as advocacy and activism tools in a manner similar to Grimes/Parker et al. (Grimes et al. 2008; Parker et al. 2012) as they reflect the changes in food quality and in turn the quality of life experienced by refugees.

Furthermore, two participants expressed interest in using technologies such as Facebook to access job opportunities that would allow them to work from home. Indeed, participants highlighted that given that they have to stay at home and 
look after their children, it is only feasible for them to find remote work or in the case of $\mathrm{P} 2$ have clients come to them. The move towards using social media as an avenue to generate income based on financial needs has been termed by Hui et al. (2018) as necessity-driven entrepreneurship. In the context of the refugee participants we engaged with, we found that technologies supporting such work models (Hui et al. 2018) should support more local level engagements that would give participants access to remote work with required offline engagements being more local. This is especially true for the participant that identified that even remote work might require travel that they cannot afford for a face-to-face interview. The participant wanting to set up a Facebook page for her business expressed difficulty in doing so. Therefore, we need to consider how global social media tools such as Facebook can be tailored to support individuals with low technological literacies in using their entrepreneurial services. Additionally, given that some participants reported that they sometimes discontinue their Wi-Fi connections in winter, due lower financial income, we need to consider how sustainable such entrepreneurship models are in contexts of precarious connectivity.

In relation to negotiating transactions, participants' co-constructed narratives highlighted that refugees practice negotiating with service providers that enable them to delay payments in order to better meet their food needs. The finding of participants' negotiations of payments resonates with previous findings by Vyas and Dillahunt (2017) where they found that low socio-economic status individuals in Australia negotiate more manageable payment schedules with service providers. However, in that context, such negotiations are formal negotiations with established water and energy service providers. This contrasts with the context in which refugees are informally negotiating payments - with local host community members with no definitive schedules. Payments are made when money is available and/or when they are pressured by service providers. The narratives coconstructed by participants highlighted that their negotiations with local service providers, such as the landlord and bus driver, are dependent on the service providers being understanding of the situation of refugees. Such understandings can be furthered through making more visible the experiences of refugees as tools for advocacy, as in Parker et al. (2012), and in supporting refugees in connecting with their host community (Almohamed et al. 2017).

\subsection{Designing for sharing}

Sharing economy models have been identified as possible avenues through which individuals in low socio-economic communities can cope with poverty (Botsman 2014). In contexts of poverty, people rely heavily on their social networks to barter skills and resources (Dillahunt 2014; Snow et al. 2017). However, participants were cautious in exploring the potential for technologies to further leverage their sharing practices within the community. Our findings show that within refugee social networks, scarce resources make the sharing of resources more 
challenging. When exploring the possibility of the use of sharing platforms to cope with food insecurity, participants strongly indicated that given that they are all experiencing poverty, it is difficult for them to share resources any further within the community. Furthermore, participants highlighted that their willingness to share resources, that are situated within households, is restricted by their want to maintain their household privacy.

Instead, participants emphasized that other forms of sharing economies that enable them to collectively negotiate may better support them in coping with food insecurity. Participants narrated how their limited access to transportation makes it difficult to access shops with more competitive prices. Limited transportation has been previously identified as a barrier to accessing healthcare facilities among Syrian refugees in Lebanon (Reese Masterson et al. 2014; Talhouk et al. 2016). Here we find that new models of sharing economies, such as that explored by Dillahunt et al. (2019) where online grocery delivery systems were found to improve access to healthy food at a low cost can be applied to this refugee community's context.

Narratives also reflected collaboration amongst refugee participants to purchase food together in order to make it more affordable. Such instances enabled them to buy food products such as olive oil, which is considered a staple in Middle Eastern food. Participants indicated that technologies may enable them to further leverage such practices by helping them identify products that they can cut costs on by purchasing collectively. Such practices are more akin to alternative food networks (Moragues-Faus 2017) and food democracies (Prost et al. 2018) in which communities come together to collectively purchase food. However, such models have typically been focused on enabling communities to leverage their agency in sourcing more sustainable food directly from food producers (Goodman et al. 2012; Moragues-Faus 2017) rather than in response to poverty. Therefore, applying such models using technologies within refugee contexts needs to be further explored as a means of supporting refugees in coping with food insecurity.

\section{Conclusions}

This study brought to the surface the experiences of a refugee community in coping with food insecurity in Lebanon. Our findings show that refugee experiences constituted adapting to their new context of poverty, navigating the aid system, negotiating with service providers and shop owners and sharing resources. In our discussion we identify how different technologies may support refugee food security through the sharing of information and facilitating the practices that refugees employ to cope with food insecurity. The technologies proposed in the discussion warrant further investigation and design research that can build on the findings presented in this paper. Furthermore, refugee participants were found 
to share resources amongst themselves to cope with food insecurity however the limited resources available to them makes such sharing models restricted. Therefore, further research is needed to explore the design of technologies that mediate sharing economies that enable collective action when negotiating with stakeholders, which was considered to be an acceptable sharing practice by participants within this context.

Acknowledgements We would first like to thank the women that participated in this study for letting Reem in to their homes and for sharing their experiences. Secondly, we would like to thank our anonymous reviewers for the constructive feedback and care they have provided.

Funding This research was funded by an EPSRC award EP/L016176/1 (Centre for Doctoral Training in Digital Civics) and Northumbria University.

Declarations

Conflicts of interest All authors declare that they have no conflicts of interest.

Open Access This article is licensed under a Creative Commons Attribution 4.0 International License, which permits use, sharing, adaptation, distribution and reproduction in any medium or format, as long as you give appropriate credit to the original author(s) and the source, provide a link to the Creative Commons licence, and indicate if changes were made. The images or other third party material in this article are included in the article's Creative Commons licence, unless indicated otherwise in a credit line to the material. If material is not included in the article's Creative Commons licence and your intended use is not permitted by statutory regulation or exceeds the permitted use, you will need to obtain permission directly from the copyright holder. To view a copy of this licence, visit http://creativecommons.org/licenses/by/4.0/.

\section{References}

Almohamed, Asam; Dhval Vyas; and Jinglan Zhang (2018). Designing for Refugees: Insights from Design Workshop. In OzCHI'18: Proceedings of the Australian Conference on Human - Computer Interaction, Melbourne, Australia, 4 December - 7 December 2018. New York: ACM Press, pp. 92-96.

Almohamed, Asam; Dhval Vyas; and Jinglan Zhang (2017). Rebuilding social capital: Engaging newly arrived refugees in participatory design. In OzCHI'19: Proceedings of the Australian Conference on Computer-Human Interaction, Brisbane, Australia, 28 November - 1 December 2017. New York: ACM Press, pp. 59-67.

Baranoff, Jennifer R.; Israle Gonzales; Jay Liu; Heidi Yan; and Jimin Zheng (2015). Lantern: Empowering Refugees Through Community-Generated Guidance Using Near Field 
Communication. In CHI EA'15: Proceedings of the Conference Extended Abstracts on Human Factors in Computing Systems, Seoul, Korea, 18 April-23 April 2015. New York: ACM Press, pp. 7-12.

Botsman, Rachel (2014). Sharing's Not Just for Start-Ups. Harvard Business Review, September, pp. 23-26.

Braun, Virginia; and Victoria Clarke (2013). Successful Qualitative Research: A Practical Guide for Beginners. London: SAGE.

Chaaban, Jad; Nisreen Salti; Hala Ghattas; Alexandra Irani; Tala Ismail; and Lara Batlouni (2015). Survey on the Socioeconomic Status of Palestine Refugees in Lebanon 2015. Beirut: UNRWA

Chamma, Jana; and Nasser Yassin (2016). The Informal Adaptive Mechanisms among Syrian Refugees and Marginalised Host Communities in Lebanon. Online Resource. London School of Economics. http://eprints.lse.ac.uk/79359/. Accessed 7 December 2021.

Comber, Rob; Jettie Hoohout; Aart Van Halteren; Paula Moynihan; and Patrick Olivier (2013). Food Practices as Situated Action: Exploring and designing for everyday food practices with households. In CHI'13: Proceedings of the ACM Conference on Human Factors in Computing Systems, Paris, France, 27 April - 2 May 2013. New York: ACM Press, pp. 2457-2466.

Creswell, John W.; and Dana L. Miller (2010). Determining Validity in Qualitative Inquiry. Theory into Practice. vol. 39, no. 3, pp.124-130.

Dillahunt, Tawanna R (2014). Fostering Social Capital in Economically Distressed Communities. In CHI'14: Proceedigns of the ACM Conference on Human Factors in Computing Systems, Toronto, Canada, 26 April - 1 May 2014. New York: ACM Press, pp. 531-540.

Dillahunt, Tawanna R; Sylvia Simioni; and Xuecong Xu (2019). Online Grocery Delivery Services: An Opportunity to Address Food Disparities in Transportation-scarce Areas. In CHI'19: Proceedings of the ACM Conference on Human Factors in Computing Systems, Glasgow, United Kingdom, 4 May - 9 May 2019. New York: ACM Press, pp. 649, 1-15.

Dombrowski, Lynne; Jed R. Brubaker; Sen H. Hirani; Melissa Mazmanian; and Gillian R. Hayes (2013). It Takes a Network to Get Dinner: Designing Location- Based Systems to Address Local Food Needs. In Ubicomp'13: Proceedings of the ACM International Joint Conference on Pervasive and Ubiquitous Computing, Zurich, Switzerland, 8 September - 12 September 2013. New York: ACM Press, pp. 519-528.

Duarte, Ana Maria Bustamante; Auriol Degbelo; and Christian Kray (2018). Exploring Forced Migrants (Re)settlement \& the Role of Digital Services. In ECSCW'18: Proceedings of European Conference on Computer-Supported Cooperative Work, Nancy, France, 4 June - 8 June 2018. Troyes: EUSSET, pp. 1-18.

El-Masri, Roula; Claire Harvey; and Rosa Garwood (2013). Shifting Sands: Changing gender roles among refugees in Lebanon. Oxford: Oxfam GB.

Fisher, Karen E.; Reem Talhouk; Katya Yefimova; Dalya Al-Shahrabi; Eiad Yafi; Sam Ewald; and Rob Comber (2017). Za'atari Refugee Cookbook: Relevance, Challenges and Design Considerations. In CHI EA'17 Proceedings of the CHI Conference Extended Abstracts on Human Factors in Computing Systems, Denver, United States, 6 May - 11 May 2017. New York: ACM Press, pp. 2567-2583.

Goodman, David E.; Melanie DuPuis; and Micheal K. Goodman (2012). Alternative Food Networks. London: Routledge.

Grimes, Andrea; Martin Bednar; Jay David Bolter; and Rebecca E. Grinter (2008). EatWell: sharing nutrition-related memories in a low-income community. In CSCW'08: Proceedings of the ACM Conference on Computer Supported Cooperative Work, San Diego, United States, 8 November- 12 November 2008. New York: ACM Press pp. 87-96.

Hui, Julie; Kentaro Toyama; Joyojeet Pal; and Tawanna R. Dillahunt (2018). Making a living my way: Necessity-driven entrepreneurship in resource-constrained communities. Proceedings 
of the ACM on Human-Computer Interaction (PACMHCI), vol. 2, no. CSCW, November 2018, pp. 71-95.

Irani, Azalea; Kriti Nelavelli; Kristin Hare; Paula Bondal; and Neha Kumar (2018). Refuge Tech: An Assets-Based Approach to Refugee Resettlement qualitative methods. In CHI EA'18: Proceedings of the CHI Conference Extended Abstracts on Human Factors in Computing Systems, Montreal, Canada, 21 April - 26 April 2018. New York: ACM Press, pp. LBW554, 1-6.

Kaye, Joseph Jofish; Mary Mccuistion; Rebecca Gulotta; and David A. Shamma (2014). Money Talks: Tracking Personal Finances. In CHI'14: Proceedings of the ACM Conference on Human Factors in Computing Systems, Toronto, Canada, 26 April - 1 May 2014. New York: ACM Press, pp. 521-530.

Maitland, Carleen; Brian Tomaszewski; Elizabeth Belding; Karen Fisher; Xu Ying; Danny Iland; Paul Schmitt; and Amira Majid (2015). Youth Mobile Phone and Internet Use January 2015 Za'atari Camp. State College, United States: Penn State University.

Moragues-Faus, Ana (2017). Emancipatory or Neoliberal Food Politics? Exploring the "Politics of Collectivity" of Buying Groups in the Search for Egalitarian Food Democracies. Antipode, vol. 49, no. 2, August 2016, pp. 455-476.

Nabil, Sara; Reem Talhouk; Julie Trueman; David S. Kirk; Simon Bowen; and Peter Wright (2018). Decorating Public and Private Spaces: Identity and Pride in a Refugee Camp. In CHI EA'18: Extended Abstracts of The CHI Conference on Human Factors in Computing Systems, Montreal, Canada, 21 April - 26 April 2018. New York: ACM Press, pp. LBW552, 1-6.

Parker, Andrea Grimes; Vasudhara Kantroo; Hee Rin Lee; Miguel Osornio; Mansi Sharma; and Rebecca Grinter (2012). Health promotion as activism: building community capacity to effect social change. In CHI'12: Proceedings of Conference on Human Factors in Computing Systems, Austin, United States, 5 May - 10 May 2012. New York: ACM Press, pp. 99-108.

Prost, Sebastian; Clara Crivellaro; Andy Haddon; and Rob Comber (2018). Food Democracy in the Making: Designing with Local Food Networks. In CHI'18: Proceedings of the CHI Conference on Human Factors in Computing Systems, Montreal, Canada, 21 April - 26 April 2018. New York: ACM Press, pp. 333, 1-14.

Prost, Sebatian; Vasilis Vlachokyriakos; Jane Midgley; Graeme Heron; Kahina Meziant; and Clara Crivellaro (2019). Infrastructuring food democracy: The formation of a local food hub in the context of socio-economic deprivation. Proceedings of the ACM on Human-Computer Interaction (PACMHCI), vol. 3, no. CSCW, November 2019, pp. 57, 1-27.

Masterson, Amelia Reese; Jinan Usta; Jhumka Gupta; and Adrienne S. Ettinger (2014). Assessment of reproductive health and violence against women among displaced Syrians in Lebanon. BMC Women's Health, vol. 14, no. 1, pp. 25.

Sabie, Dina; Reem Talhouk; Cansu E. Dedeoglu; Carleen Maitland; Volker Wulf; Eiad Yafi; Samar Sabie; Asam Almohamed; Safa'a Abujarour; Kahina Le Louvier; Faheem Hussain; and Syed Ishtiaque Ahmed (2021). Migration and Mobility in HCI: Rethinking Boundaries, Methods, and Impact. In CHI EA'21: Proceedings of the Extended Abstracts of the CHI Conference on Human Factors in Computing Systems, Yokohama, Japan, 8 May - 13 May 2021. New York: ACM Press, pp. 97, 1-6.

Sabie, Samar; Jay Chen; Azza Abouzeid; Fatma Hashim; Harleen Kahlon; and Steve Easterbook (2017). Shelter Dynamics in Refugee and IDP Camps: Customization, Permanency, and Opportunities. In Limits'17: Proceedings of the Workshop on Computing Within Limits, Santa Barbara, United States, 22 June - 24 June 2017. New York: ACM Press, pp. 11-20.

Ghattas, Hala; Jad Chaaban; Nisreen Salti; Alexandra Irani; Tala Ismail; and Lara Batlouni (2018). Poverty, food insecurity, and health of Palestinian refugees in Lebanon and recently displaced from Syria to Lebanon: findings from the 2015 socioeconomic household survey. The Lancet, vol. 391, no. 1, pp. S11. 
Schmitt, Paul; Daniel Iland; Elizabeth Belding; Brian Tomaszewski; Ying Xu; and Carleen Maitland (2016). Community-Level Access Divides: A Refugee Camp Case Study. In ICTD'16: Proceedings of the Conference on Information and Communication Technologies and Development, Ann Arbor, United States, 3 June - 6 June 2016. New York: ACM Press, pp. 25, 1-11.

Schreieck, Maximilian; Jonas Zitzelsberger; Sebastian Siepe; Manuel Wiesche; and Helmut Krcmar (2017). Supporting Refugees in Every Day Life - Intercultural Design Evaluation of an Application for Local Information. In PACIS 2017: Proceedings of the Pacific Asia Conference on Information Systems, Langkawi Island, Malaysia, 16 July- 20 July 2017. AIS Library, pp. 1-12.

Snow, Stephen; Dhaval Vyas; and Margot Brereton (2017). Sharing, Saving, and Living Well on Less: Supporting Social Connectedness to Mitigate Financial Hardship. International Journal of Human-Computer Interaction (IJHCI), vol. 33, no. 5, pp. 345-356.

Talhouk, Reem; Madeline Balaam; Austin L. Toombs; Chaza Akik; Hala Ghattas; Vera AraújoSoares; Balsam Ahmad; and Kyle Montague (2019a). Involving Syrian Refugees in Design Research: Lessons Learnt from the Field. In DIS'19: Proccedings of the conference on Designing Interactive Systems, San Diego, United States, 23 June - 28 June 2019. New York: ACM Press, pp. 1583-1594.

Talhouk, Reem; Kyle Montague; Andrew Garbett; Vera Araújo-Soares; Chaza Akik; Hala Ghattas; Balsam Ahmad; and Madeline Balaam (2019b). A call for embedding dignity in humanitarian technologies. In C\&T'19: ACM International Conference on Communities and Technologies, Vienna, Austria, 3 June - 7 June 2019. New York: ACM Press, pp. 1-4.

Talhouk, Reem; Tom Bartindale; Kyle Montague; Sandra Mesmar; Chaza Akik; Ali Ghassani; Martine Najem; Hala Ghattas; Patrick Olivier; and Madeline Balaam (2017). Implications of Synchronous IVR Radio on Syrian Refugee Health and Community Dynamics. In $C \& T^{\prime} 17$ : Proceedings of the International Conference on Communities and Technologies, Troyes, France, 26 June - 30 June 2017. New York: ACM Press, pp. 1-10.

Talhouk, Reem; Lizzie Coles-Kemp; Rikke B. Jensen; Madeline Balaam; Andrew Garbett; Hala Ghattas; Vera Araújo-Soares; Balsam Ahmad; and Kyle Montague (2020). Food Aid Technology: The Experience of a Syrian Refugee Community in Coping with Food Insecurity. Proceedings of the ACM on Human-Computer Interaction (PACMHCI), vol. 4, no. CSCW2, October 2020, pp. 134, 1-25.

Talhouk, Reem; Sandra Mesmar; Anja Thieme; Madeline Balaam; Patrick Olivier; Chaza Akik; and Hala Ghattas (2016). Syrian Refugees and Digital Health in Lebanon: Opportunities for Improving Antenatal Health. In CHI'16: Proceedings of the CHI Conference on Human Factors in Computing Systems, San Jose, United States, 7 May - 12 May 2016. New York: ACM Press, pp. 331-342.

UNHCR (2016). Connecting Refugees. Report. UNHCR. http://www.unhcr.org/uk/publications/ operations/5770d43c4/connecting-refugees.html. Accessed 7 December 2021.

UNHCR (2020). Syria Regional Refugee Response. Report. UNHCR. http://data.unhcr.org/ syrianrefugees/country.php?id=122. Accessed 7 December 2021.

UNHCR, Unicef, WFP, \& Inter-Agency Coordination (2019). VASyR 2019. Report. UNHCR. https://reliefweb.int/sites/reliefweb.int/files/resources/73118.pdf. Accessed 7 December 2021.

Vyas, Dhaval; and Tawanna Dillahunt (2017). Everyday Resilience: Supporting Resilient Strategies among Low-socioeconomic-status Communities. Proceedings of the ACM on Human-Computer Interaction (PACMHCI), vol. 1, no. CSCW, November 2017, pp. 105, 1-21.

Vyas, Dhaval; Stephen Snow; Paul Roe and Margot Brereton (2016). Social Organization of Household Finance: Understanding Artful Financial Systems in the Home. In CSCW'16: Proceedings of the ACM Conference on Computer-Supported Cooperative Work \& Social Computing, San Francisco, United States, 27 February - 2 March 2016. New York: ACM Press, pp. 1775-1786. 
Wallace, Jayne; John McCarthy; Peter Wright and Patrick Olivier (2013). Making design probes work. In CHI'13: Proceedings of Conference on Human Factors in Computing Systems, Paris, France, 27 April - 2 May 2013. New York: ACM Press, pp. 3441-3450.

Weibert, Anne; Max, Kruger; Konstantin Aal; Setareh Sadat Salehee; Renad Khatib; David Randall; and Volker Wulf (2019). Finding language classes: Designing a digital language wizard with refugees and migrants. Proceedings of the ACM on Human-Computer Interaction (PACMHCI), vol. 3, no. CSCW, November 2019, pp. 116. 1-23.

World Food Program (2018). Building Blocks. Webpage. WFP Innovation. http://innovation.wfp. org/project/building-blocks. Accessed 7 December 2021

Wright, Peter; and John McCarthy (2010). Experience-Centered Design: Designers, Users, and Communities in Dialogue. In John M. Carroll (Ed.), Synthesis Lectures on Human-Centered Informatics. San Rafael: Morgan \& Claypool, pp.1-123.

$\mathrm{Xu}$, Ying; and Carleen Maitland (2016). Communication Behaviors When Displaced: A Case Study of Za'atari Syrian Refugee Camp. In ICTD'16: Proceedings of the International Conference on Information and Communication Technologies and Development, Ann Arbor, United States, 3 June - 6 June 2016. New York: ACM Press, pp. 58, 1-4.

$\mathrm{Xu}$, Ying; Carleen Maitland; and Brian Tomaszewski (2015). Promoting Participatory Community Building in Refugee Camps with Mapping Technology. In ICTD'15: Proceedings of the International Conference on Information and Communication Technologies and Development, Singapore, Singapore, 15 May - 18 May 2015. New York: ACM Press, pp. 67, 1-4.

Yafi, Eiad; Katya Yefimova; and Karen Fisher (2018). Young Hackers: Hacking Technology at Za'atari Syrian Refugee Camp. In CHI EA' 18: Proceedings of the Extended Abstracts CHI Conference on Human Factors in Computing Systems, Montreal, Canada, 21 April- 26 April 2018. New York: ACM Press, pp. CS21, 1-8.

Publisher's Note Springer Nature remains neutral with regard to jurisdictional claims in published maps and institutional affiliations. 